\title{
Genome Editing: Methods and Application in Plant Pathology
}

\author{
Lokesh Yadav*, Promil Kapoor and Ashwani Kumar \\ Department of Plant Pathology, CCS Haryana Agricultural University, Hisar- 125004, India \\ *Corresponding author
}

\section{Keywords}

Genome editing,

Plant pathology,

Meganuclease,

Cas9

Article Info

Accepted:

12 April 2019

Available Online:

10 May 2019

\section{A B S T R A C T}

Genome manipulation technology is one of emerging field which brings real revolution in genetic engineering and biotechnology. Genome editing technique is consistent for improving average yield to achieve the growing demands of world's existing food famine. Because of their advantages such as simplicity, efficiency, high specificity and amenability to multiplexing, genome editing technologies are revolutionizing the way crop breeding is done and paving the way for next generation breeding. In different areas including plant research, new breeding techniques are of great concern such as plant pathogen resistance, developmental biology and abiotic stress tolerance. Meganucleases (MNs), zinc finger nucleases (ZFNs), transcription activator-like effector nucleases (TALENs) and clustered regularly interspaced short palindromic repeats (CRISPR)/CRISPR associated protein 9 (Cas9) are the four types of nucleases used in genome editing (Jaganathan et al., 2018). Homing endonuclease/meganuclease enzymes were the first among synthetic nucleases, to be used for genome editing purposes in plants, including Arabidopsis and maize. The recognition sites of homing endonucleases do not occur naturally in the plant genome, and this is the main limitation of these endonucleases as plant genome editing tools (Kumar \& Jain, 2015). Chimeric restriction endonucleases were created as the first ZFNs and were shown to have in vitro activity. TALENs are similar to ZFNs and the DNA-binding domain is composed of highly conserved repeats derived from transcription activator-like effectors (TALEs), which are proteins secreted by Xanthomonas to alter transcription of genes in host plant cells. The type II CRISPR system is the most widely used from Streptococcus pyogenes (Amardeep et al., 2017). Protection is provided in bacteria, the type-II CRISPR system against DNA from invading viruses and plasmids via RNA-guided DNA cleavage by Cas proteins. Indeed, these emerging technologies have the ability to manipulate and study model organisms and these technologies promise to expand our ability to explore and alter any genome and constitute a new and promising paradigm to understand and treat disease (Gaj et al., 2013).

\section{Background}

Genetic engineering can accelerate the advancement of improved crops and animals. Firstly genetically modified (GM) crops were popularized in 1996. From that point forward the cultivated area has expanded 100 overlays with 28 nations growing these crops. About 2000 examinations have been distributed assessing the wellbeing of GM crops; thus far 
the outcomes recommend that the effect of GM crops on nourishment and ecological security are very little not quite the same as expectedly conventional crops produced. Nevertheless, there is continued uncertainty toward this technology (James, 2014). The field of genome altering is encountering quick development as new techniques and advances keep on rising. Utilizing genome editing to increase agriculture productivity is required as the total population is relied upon to develop to 9.6 billion by 2050 while the area of arable land diminishes (Ray et al., 2013). Besides potential for boosting crop yields, genome editing is now one of the best tools for carrying out reverse genetics and is emerging as an especially versatile tool for studying basic biology. Genetically modified plants are separated from regular transgenic plants as they may not join remote DNA.

In spite of the fact that genome editing can be utilized to bring outside DNA into the genome, it might just include changes of a couple of base combines in the plant's own DNA. This qualification makes genome altering a novel and amazing tool. Genome editing technique is performing outstandingly for increasing crop yield and proved to be important tool to fulfil the demand of the world's population and food famine and to become a realistic and environment friendly agriculture system, to more precise, fruitful, gainful approach. Moreover, public discomfort for utilizing GM crops is further intensified when speaking on introduction of 'foreign' genes from faintly related organisms as this is apparent as 'unnatural' despite emerging evidence to the contrary. For example, natural sweet potato varieties are now known to harbour $\mathrm{T}$-genes from Agrobacterium tumefaciens (Verma, 2013; Lucht, 2015). These new and advanced strategies are shortly reviewed here and shown that how these are reliable tool for improving plants in desirable way.

\section{Introduction}

Plant breeding has been the most successful approach for developing new crop varieties since domestication occurred, making possible major advances in feeding the world and societal development. Crops are susceptible to a large set of pathogens including fungi, bacteria, and viruses, which cause important economic losses (FAO, 2017). Current crop improvement strategies include artificially mutating genes by chemical mutagenesis and ionizing radiation (Pathirana, 2011) or introducing new genes through Agrobacterium tumefaciens-mediated transformation (Gelvin, 2003) and direct gene transfer (Dunwell, 2014). The first strategy, known as 'classical mutagenesis', is limited by the fact that the genetic changes are induced randomly, so it is necessary to screen a large number of individuals to identify those carrying a mutation in the gene of interest and it then still remains unclear which alterations (if any) the other random induced mutations may cause. The latter transgenic approach also relies on random integration of transgene and faces many regulatory and public acceptance hurdles. With current breeding technologies, yield increases are still not currently projected to meet the demand of a growing population, diet changes and the use of bio fuels (Ray et al., 2013).

However, conventional genetic engineering strategy has several issues and limitations, one of which is the complexity associated with the manipulation of large genomes of higher plants (Nemudryi et al., 2014). Currently, several tools that help to solve the problems of precise genome editing of plants are at scientists' disposal. In 1996, for the first time, it was shown that protein domains such as "Zinc fingers" coupled with FokI endonuclease domains act as site-specific nucleases (zinc finger nucleases (ZFNs)), which cleave the DNA in vitro in strictly 
defined regions (Kim et al., 1996). Such a chimeric protein has a modular structure, because each of the "Zinc finger" domains recognizes one triplet of nucleotides. This method became the basis for the editing of cultured cells, including model and nonmodel plants (Gaj et al., 2013). The challenge remains, however, to convert the enormous amount of genomic data into functional knowledge and subsequently to determine how genotype influences phenotype. Homologous recombination for targeting gene expression is a powerful method for providing information on gene function (Capecchi, 2005). However, the low efficiency, long duration of studies, mutagenic effects and offtarget effects has troubled the application of this technique. Although RNAi technology for targeted knocking-down gene expression proved to be a rapid and inexpensive, compared to homologous recombination, hindering gene expression via RNAi is underutilized (McManus and Sharp, 2002). Genome editing uses more recent knowledge and technology to enable a specific area of the genome to be modified, thereby increasing the precision of the correction or insertion, preventing cell toxicity and offering perfect reproducibility (Voytas and Gao, 2014; Voytas, 2013). Genome engineering might prove to be more acceptable to the public than plants genetically engineered with foreign DNA in their genomes. It occurs also as a natural process without artificial genetic engineering. Viruses or subviral RNA-agents are used as vectoral agents to edit genetic sequences (Witzany, 2011). Genetic modification using transposon will affect the level of expression of the induced gene produced by the random insertion positions of genes, while RNAi has temporary knockdown effects, unpredictable off-target influence and too much background noise (Chen et al., 2014; Martin and Caplen, 2007; Dietzl et al., 2007; Gonczy et al., 2000). Alternative strategies were provided for the combined use of multiple site-specific recombinase systems for genome engineering to precisely insert transgenes into a pre-determined locus, and removal of unwanted selectable marker genes (Wang et al., 2011; Allen and Weeks, 2005; Allen and Weeks, 2009; Araki et al., 1995; Jia et al., 2006).

\section{Mechanisms of genome editing systems}

This core technology - commonly referred to as 'genome editing' - is based on the use of engineered nucleases composed of sequencespecific DNA-binding domains fused to a nonspecific DNA cleavage module (Urnov et al., 2010; Carroll, 2011).

Novel genome editing tools, also referred to as genome editing with engineered nuclease (GEEN) technologies, allow cleavage and rejoining of DNA molecules in specified sites to successfully modify the hereditary material of cells. To this end, special enzymes such as restriction endonucleases and ligase can be used for cleaving and rejoining of DNA molecules in small genomes like bacterial and viral genomes. However, using restriction endonucleases and ligases, it is extremely difficult to manipulate large and complex genomes of higher organisms, including plant genomes.

The problem is that the restriction endonucleases can only "target" relatively short DNA sequences. While such specificity is enough for short DNA viruses and bacteria, it is not sufficient to work with large plant genomes. The first efforts to create methods for the editing of complex genomes were associated with the designing of "artificial enzymes" as oligonucleotides (short nucleotide sequences) that could selectively bind to specific sequences in the structure of the target DNA and have chemical groups capable of cleaving DNA (Knorre and Vlasov, 1985). Moreover, many studies have 
used physical, chemical, or biological (e.g., TDNA/ transposon insertion) mutagenesis to identify mutants and construct mutant libraries corresponding to tens of thousands of genes in model plants, such as Arabidopsis (Kuromori et al., 2006) and rice (Wu et al., 2003; Yang et al., 2013). The emergence of programmable sequence-specific nucleases (SSNs) provided a breakthrough in genome manipulation. SSNs can induce doublestranded breaks (DSBs) in specific chromosomal sites. The resulting DSBs can be repaired by the error-prone nonhomologous end joining (NHEJ) pathway, often producing nucleotide insertions, deletions, and substitutions. Another independent pathway, homology-directed repair (HDR), also can repair the DSBs if homologous donor templates are present at the time of DSB formation (Symington and Gautier, 2011) (Fig. 1-4).

\section{Meganucleases}

Meganucleases (MegaN) are naturally occurring endonucleases, which were discovered in the late 1980s. They belong to endonuclease family that can recognize and cut large DNA sequences (from 12 to 40 base pairs) unique or nearly-so in most genomes (Gallagher et al., 2014). The concept of gene editing with programmable nucleases began with meganucleases and has been developed over the past two decade. Meganucleases are homing endonucleases that recognize a large DNA target sequence and make a doublestranded break. Multiple families of homing endonucleases exist but the LAGLIDADG family is the most common one for genome engineering. These function as homodimers and cleave the DNA using two compact active sites (Jurica et al., 1998). Direct interactions between the DNA and protein side chains recognize up to $18 \mathrm{bp}$ of target DNA and changing the amino acid sequence of endonucleases alters their specificity
(Seligman et al., 2002). Two endonucleases fused together recognize a longer chimeric DNA sequence (Chevalier et al.,, 2002) and they can be engineered to recognize entirely novel sequences (Smith et al., 2006). In practice meganucleases are difficult to engineer because the DNA-binding and endonuclease activities reside on the same domain, and their development has stalled compared to other programmable nucleases. Another approach was developed by Precision Biosciences, Inc. where they developed a fully rational design process called the directed nuclease editor (DNE), capable of creating highly specific engineered meganucleases that successfully target and modify a user-defined location in a genome (Ashworth et al., 2010).

A disadvantage of meganuclease is that the construction of sequence specific enzymes for all possible sequences is costly and time consuming compared to other SSN systems. Each new genome-engineering target therefore requires an initial protein engineering stage to produce a custom meganuclease. Therefore, meganucleases proved technically challenging to work with and are also hindered by patent disputes (Smith et al., 2011).

\section{Zinc Finger Nuclease (ZFNs)}

ZFNs are fusion proteins consisting of "zinc finger" domains obtained from transcription factors attached to the endonuclease domain from the bacterial Fok I restriction enzyme. Zinc fingers $(\mathrm{ZF})$ are proteins composed of conjugated $\mathrm{Cys}^{2} \mathrm{His}^{2}$ motifs that each recognizes a specific nucleotide triplet based on the residues in their $\alpha$-helix. These are capable of sequence-specific DNA binding, fused to a nuclease domain for DNA cleavage. Each zinc finger domain recognizes a 3- base pair DNA sequence, and tandem domains can potentially bind to an extended 
nucleotide sequence that is unique to a genome. The first $\mathrm{ZFNs}$ were created as chimeric restriction endonucleases and were shown to have in vitro activity (Kim et al., 1996). Several approaches are used to design specific zinc finger nucleases for the chosen sequences. These synthetic proteins could be used in editing of a specific gene by fusing it with the catalytic domain of the FokI endonuclease in order to induce a targeted DNA break, and therefore to use these proteins as genome engineering tools (Rebar et al., 2002). The DNA-binding domain of ZFNs contains several ZF motifs whose number can be changed. Three ZF motifs are believed to be the minimum to achieve the adequate specificity and affinity. Although adding more $\mathrm{ZF}$ motifs may enhance the binding specificity, it also increases the difficulty of ZFP gene synthesis and searching for an appropriate site. Three or four $\mathrm{ZF}$ motifs have been used wildly and successfully for strictly cleavage in genome (Bibikova, 2003). The identification of $\mathrm{ZF}$ motifs that specifically recognize each of the 64 possible DNA triplets is a key step towards the construction of "artificial" DNA-binding proteins that recognize any pre-determined target sequence within a plant or mammalian genome (Porteus, 2006). The design of ZFNs is considered difficult due to the complex nature of the interaction between zinc fingers and DNA and further limitations imposed by context-dependent specificity. The Fok I nuclease domain requires dimerization to cleave DNA and therefore two ZFNs with their $\mathrm{C}$-terminal regions are needed to bind opposite DNA strands of the cleavage site (separated by 5-7 bp). The FokI domain has been crucial to the success of ZFNs, as it possesses several characteristics that support the goal of targeted cleavage within complex genomes. The ZFN monomer can cut the target site if the two ZF-binding sites are palindromic. This spacing allows the two inactive FokI nuclease domains to dimerize, become active as a nuclease and create a double-stranded DNA break (DSB) in the middle of the spacer region between the two ZFNs. The DSB is often repaired by the NHEJ DNA repair mechanism that is errorprone. That is, during the repair process, usually small number of nucleotides can be deleted or added at the cleavage site (Sander, 2011). Several optimizations need to be made in order to improve editing plant genomes using ZFN mediated targeting, including the reduction of toxicity of the nucleases, the appropriate choice of the plant tissue for targeting, the introduction of enzyme activity, the lack of off-target mutagenesis, and a reliable detection of mutated cases (Puchta and Hohn, 2010).

\section{Transcription activator like effector nucleases (TALENs)}

In 2011, another method was developed for increasing efficiency, safety and accessibility of genome editing - called TALEN (Transcription Activator-Like Effector Nucleases) system. The TALEN system developed from the transcription activatorlike effectors (TALES) produced by the phytopathogenic bacteria Xanthomonas genus (Boch and Bonas, 2010; Urnov et al., 2010). Transcription activator like effector nucleases (TALENs) have rapidly emerged as an alternative to ZFNs for genome editing and introducing targeted DSBs. TALENs are similar to ZFNs and comprise a non-specific Fok I nuclease domain fused to a customizable DNA-binding domain. The DNA-binding domain is composed of highly conserved repeats derived from transcription activator-like effectors (TALEs), which are proteins secreted by Xanthomonas bacteria to alter transcription of genes in host plant cells (Boch et al., 2010). These bacteria are pathogens of crop plants, such as rice, pepper, and tomato; and they cause significant economic damage to agriculture, which was 
the motivation for their thorough study. The bacteria were found to secrete effector proteins (TALEs) to the cytoplasm of plant cells, there they enter the nucleus, bind to effector-specific promoter sequences, and activate the expression of individual plant genes, which can either benefit the bacterium or trigger host defences (Kay et al., 2007). Co-crystal structures of TALE DNA-binding domains bound to their cognate sites have shown that individual repeats comprise twohelix v-shaped bundles that stack to form a superhelix around the DNA and the hypervariable residues at positions 12 and 13 are positioned in the DNA major-groove. The residues at position 8 and position 12 within the same repeat make a contact with each other that may stabilize the structure of the domain while the residues at position 13 can make base-specific contacts with the DNA (Mak et al., 2012).

The big obstacle in applying TALEN system is in constructing the vector with suitable monomers for binding the target DNA in the genome. Several techniques have been conducted for constructing TALE DNAbinding domains consisting of 20-30 or even more monomers. One of the strategies is based on standard DNA cloning using DNA restriction endonucleases and ligation monomers as first step to generate a dimers library, as a second step the Golden Gate reaction is used (Weber et al., 2011; Engler et al., 2009), which is a simultaneous ligation of several dimers in the same reaction mixture. In order to reduce the time needed to develop genetic constructs expressing TALEN, several companies have developed simple, efficient and accessible techniques for the construction of TALENs such as the Addgene Depository kit (http://www.addgene.org/ TALEN/), commercial platform from Cellestis Bioresearch which enables one to generate up to 7,200 of these constructs annually and the Fast Ligation-based Automatable Solid-phase
High-throughput (FLASH) platform as a rapid and cost-effective method (Reyon et al., 2012). Methods to modify plant genomes that do not require DNA delivery would have value in both commercial and academic settings. Luo et al., (2015) demonstrate nontransgenic plant genome engineering by introducing sequence- specific nucleases as purified protein. This approach enabled targeted mutagenesis of endogenous sequences within plant cells, while avoiding integration of foreign DNA into the genome. In the short time since the first TALENs were reported, they have proven powerful reagents for reverse genetics in multiple experimental systems. They are rapidly being employed to ameliorate genetic diseases through gene therapy and to solve challenges in agriculture.

\section{The CRISPR/Cas9 system}

Until 2013, the dominant genome editing tools were zinc finger nucleases (ZFNs) and transcription activator-like effector nucleases (TALENs) (Christian et al., 2010). Distant arrays of short repeats interspaced with unique spacers (CRISPR loci) have been observed in bacterial and archaeal genomes for a long time. Three research groups independently reported the homology of hyper variable spacer sequences with viral genome and plasmid sequences (Bolotin et al., 2005; Mojica et al., 2005; Pourcel et al., 2005). These studies hypothesized that CRISPR loci and Cas proteins could play a role in imparting immunity against transmissible genetic elements. Recently, the unique ability of the CRISPR-Cas system to degrade the genetic material of invading foreign DNA is being exploited as a genome editing tool. The CRISPR-Cas system is present in most archaeal (90\%) and many bacterial (48\%) genomes (Rousseau et al., 2009). This system has the ability to incorporate short sequences of non-self genetic material (spacers) at specific locations 
within the CRISPRs in the genome (Bhaya et al., 2011; Wiedenheft et al., 2012). Recently, the bacterial type II clustered, regularly interspaced, short palindromic repeat (CRISPR)/CRISPR-associated protein (Cas) system has attracted attention due to its ability to induce sequence specific genome editing. In bacteria, the CRISPR system provides acquired immunity against invading foreign DNA via RNA-guided DNA cleavage. The latest ground-breaking technology for genome editing is based on RNA-guided engineered nucleases, which already hold great promise due to their simplicity, efficiency and versatility. The most widely used system is the type II clustered regularly interspaced short palindromic repeat (CRISPR)/Cas9 (CRISPR-associated) system from Streptococcus pyogenes. CRISPR/Cas systems are part of the adaptive immune system of bacteria and archaea, protecting them against invading nucleic acids such as viruses by cleaving the foreign DNA in a sequence-dependent manner. A prerequisite for cleavage of the target DNA is the presence of a conserved protospacer-adjacent motif (PAM) downstream of the target DNA, which usually has the sequence 5'-NGG-3' but less frequently NAG (Jinek et al., 2012). Different variants of Cas9, such as native Cas9, Cas9 nickase, and dCas9 (nuclease-deficient Cas9), can be employed for different applications. Wild-type humanized Cas9 (hCas9) has been used in mammalian cells to generate gene knockouts (Cho et al., 2013; Cong et al., 2013; Mali et al., 2013).

Till today, genome-editing protocols have adopted three different types of Cas9 nuclease. The first Cas9 type can cut DNA site-specifically and results in the activation of DSB repair. Cellular NHEJ mechanism is used to repair DSBs (Hsu et al., 2013).

Schaeffer and Nakata, (2015) concluded that, as a consequence, insertions/deletions (indels) take place that interrupt the targeted loci.
Otherwise, if any similarity between donor template and target locus is witnessed, the DSB may be mended by HDR pathway allowing exact substitute mutations to be prepared. It cuts single strand of DNA without activation of NHEJ. As an alternative, DNA repairs took place via the HDR pathway only. Hence it produces less indel mutations (Jinek et al., 2012). Mutations in the HNH domain and RuvC domain discharge cleavage activity, but do not prevent DNA binding. Therefore, this particular variant can be utilized in sequence-specific targeting of any genome regardless of cleavage. This situation can result in edited plants exempted from current GMO regulations. So we can hope for widespread application of RNA-guided genome editing in agriculture and plant biotechnology (Amardeep et al., 2017).

\section{A comparison of CRISPR/Cas9, ZFNs and TALENs}

ZFNs and TALENs function as dimers and only protein components are required. Sequence specificity is conferred by the DNA-binding domain of each polypeptide and cleavage is carried out by the FokI nuclease domain. In contrast, the CRISPR/Cas9 system consists of a single monomeric protein and a chimeric RNA. Sequence specificity is conferred by a 20 -nt sequence in the gRNA and cleavage is mediated by the Cas 9 protein. The design of ZFNs is considered difficult due to the complex nature of the interaction between zinc fingers and DNA and further limitations imposed by context-dependent specificity. Table 1 is given below for comparison (Shah et al., 2017). In comparison, gRNA-based cleavage relies on a simple Watson-Crick base pairing with the target DNA sequence, so sophisticated protein engineering for each target is unnecessary and only $20 \mathrm{nt}$ in the gRNA need to be modified to recognize a different target. ZFNs and TALENs both carry the catalytic domain of the restriction 
endonuclease Fok I, which generates a DSB with cohesive overhangs varying in length depending on the linker and spacer. Cas 9 has two cleavage domains known as RuvC and $\mathrm{HNH}$, which cleave the target DNA three nucleotides upstream of the PAM leaving blunt ends (Jinek et al., 2012).

\section{Applications of genome editing in plants}

For functional genomics: - Genome modification of different types can be achieved through use of TALEN, CRISPR/Cas genome editing systems, ZFN and ODM. Through these several modifications can be created such as new gene insertion in specific locations, substitution or correction of gene fragments and individual genetic elements, point mutations and deletion of large regions of the nucleotide sequences (Zhang et al., 2016).

In crop improvement: -

Blast resistance in rice: - Several genome editing techniques such as CRISPR/CAS system and TALENS are frequently applied to achieve disease resistance in a crop like rice. Interaction between the TAL effectors of targeted host infection vulnerability genes and bacterial parasite Xanthomonas oryzae pv. Oryzae cause rice blast disease (Shah et al., 2018)

Aroma in rice: - Aromatic rice has primary fragrance compound.

Powdery mildew resistant wheat: - Blumeria graminis $\mathrm{f}$. sp. tritici causes powdery mildew, which is one of severe wheat crop disease, it drastically reduce yield specifically in temperate zones.

Declining of phytic acid in maize: - Through the use of genome engineering technologies, significant reduction in phytic acid concentration can be achieved. In 2009, a
ZFN was engineered to modify IPK1 gene, which is involved in regulation of bioagents of phytic acid.

Improved oleic level in soyabean oil:TALENs have been utilized to slow down the two fatty acids desaturase genes activity in soyabean i.e., FAD2 and FAD3, which are responsible for converting oleic acid to linolenic acid. This technology increased oleic acid content in plants (Haun et al., 2014) (Table 2-4).

Herbicide-resistant crops: - Genome editing technologies have achieved the target to generate herbicide resistant crops. ZFN mediated genome editing alter function of ACETOLACTATE SYNTHASE (ALS) gene by inducing point mutation at specific locus as this gene is specially targeted by imidazolinone (IMI) and sulfonylurea (SU) herbicide (Townsend et al., 2009).

\section{Limitations and risk}

Unfortunately, because of low affinity and low specificity, gene editing with ZFNs has displayed high frequencies of off-target edits and high toxicity. It is difficult, however, to construct the nuclease protein and a new TALEN protein must be generated for each DNA target site, which increases time and costs for development. However, a crucial current concern for the CRISPR/Cas9 system is the potential for higher off-target effects than with TALENs. When the sgRNA sequence recognizes partial mismatches outside the seed sequence instead of on-target sites, then off-target edits will be produced. Researchers need to consider the ecological implications of unanticipated downstream effects when genome editing is used for plant improvement. Plant genome editing represents a wide variety of potential reagents and methodologies with potential outcomes for which off-target effects may be consequential (Zhao and Wolt, 2017). 
Table.1 Comparison between different platforms of genome editing

\begin{tabular}{|c|c|c|c|c|}
\hline \multicolumn{5}{|c|}{ Platforms } \\
\hline Points & ZFNs & TALENs & CRISPR/Cas9 & Reference \\
\hline Components & $\begin{array}{l}\text { Zinc finger domain } \\
\text { Nonspecific FokI } \\
\text { nuclease domain. }\end{array}$ & $\begin{array}{l}\text { TALE DNA- binding } \\
\text { domains Nonspecific } \\
\text { FokI nuclease domain }\end{array}$ & crRNA/sgRNA & $\begin{array}{l}\text { Kumar and Jain, 2015; } \\
\text { Sauer } \text { et al., } 2016\end{array}$ \\
\hline $\begin{array}{l}\text { Structural } \\
\text { proteins }\end{array}$ & Dimeric protein & Dimeric protein & $\begin{array}{l}\text { Monomeric } \\
\text { protein }\end{array}$ & Sauer et al., 2016 \\
\hline Catalytic domain & $\begin{array}{l}\text { Restriction } \\
\text { endonuclease FokI }\end{array}$ & $\begin{array}{l}\text { Restriction } \\
\text { endonuclease FokI }\end{array}$ & $\begin{array}{l}\text { DSBs in target } \\
\text { DNA or single } \\
\text { strand DNA } \\
\text { nicks }\end{array}$ & Chen et al., 2016 \\
\hline $\begin{array}{l}\text { Length of target } \\
\text { sequence (bp) }\end{array}$ & $24-36$ & $24-59$ & $20-22$ & Chen et al., 2016 \\
\hline $\begin{array}{l}\text { Protein } \\
\text { engineering steps }\end{array}$ & Required & Required & $\begin{array}{l}\text { Should not be } \\
\text { complex to test } \\
\text { gRNA }\end{array}$ & Sauer et al.,, 2016 \\
\hline Cloning & Necessary & Necessary & Not necessary & Weeks et al., 2016 \\
\hline gRNA production & Not applicable & Not applicable & Easy to produce & Norman et al., 2016 \\
\hline Mode of action & $\begin{array}{l}\text { Double-strand breaks } \\
\text { in target DNA }\end{array}$ & $\begin{array}{l}\text { Double-strand breaks } \\
\text { in target DNA }\end{array}$ & $\begin{array}{l}\text { Double-strand } \\
\text { breaks or single- } \\
\text { strand nicks in } \\
\text { target DNA }\end{array}$ & Sauer et al., 2016 \\
\hline $\begin{array}{l}\text { Target } \\
\text { recognition } \\
\text { efficiency }\end{array}$ & High & High & High & $\begin{array}{l}\text { Kumar and Jain, 2015; } \\
\text { Sauer } \text { et al., } 2016\end{array}$ \\
\hline Mutation rate & High & Middle & Low & Gaj et al., 2013 \\
\hline $\begin{array}{l}\text { Creation of large } \\
\text { scale } \\
\text { libraries }\end{array}$ & Impossible & Technically difficult & Possible & Sauer et al., 2016 \\
\hline Multiplexing & Difficult & Difficult & Possible & Norman et al., 2016 \\
\hline
\end{tabular}

Table.2 Successful examples of genome editing in plants using ZFNs

\begin{tabular}{|c|c|c|c|c|}
\hline S. No. & Plant Name & Nuclease Type & Targeted Gene & References \\
\hline 1 & Arabidopsis & ZFN & ADH1, TT4 & Zhang et al., 2010 \\
\hline 2 & Soya bean & $\mathrm{ZFN}$ & DCL4a, DCL4b & $\begin{array}{l}\text { Curtin et al., } 2013 \\
\text { Curtin } \text { et al., } 2011\end{array}$ \\
\hline 3 & Maize & ZFN & IPK1, Zein protein 15 & Shukla et al., 2009 \\
\hline 4 & Arabidopsis & $\mathrm{ZFN}$ & ABI4, KU80 and ADH1, TT4 & $\begin{array}{l}\text { Osakabe et al., } 2010 \\
\text { Zhang } \text { et al., } 2010\end{array}$ \\
\hline 5 & Tobacco & ZFN & $\begin{array}{l}\text { SuRA, SuRB } \\
\text { (Acetolactate synthase genes) }\end{array}$ & Townsend et al., 2009 \\
\hline 6 & Cotton & ZFN & hppd, epsps & D"Halluin et al., 2013 \\
\hline
\end{tabular}


Table.3 Successful examples of genome editing in plants using TALENs

\begin{tabular}{|l|l|l|l|l|}
\hline S. No & Plant Name & Nuclease Type & Targeted Gene & References \\
\hline $\mathbf{1}$ & Arabidopsis & TALEN & $\begin{array}{l}\text { ADH1, TT4, MAPKKK1, } \\
\text { DSK2B, NATA2, GLL22a, } \\
\text { GLL22b }\end{array}$ & $\begin{array}{l}\text { Cermak } \text { et al., } 2011 \\
\text { Char } \text { et al., } 2017\end{array}$ \\
\hline $\mathbf{2}$ & Barley & TALEN & GFP (transgene) & Gurushidze et al., 2014 \\
\hline $\mathbf{3}$ & Maize & TALEN & GL2 & Char et al., 2015 \\
\hline $\mathbf{4}$ & Tomato & TALEN & PROCERA & Lor et al., 2014 \\
\hline $\mathbf{5}$ & Rice & TALEN & $\begin{array}{l}\text { 11N3, DEP1, BADH2, } \\
\text { CKX2, } \\
\text { SD1, OsSWEET14 }\end{array}$ & $\begin{array}{l}\text { Li } \text { et al., } 2012 \\
\text { Shan } \text { et al., 2013 }\end{array}$ \\
\hline $\mathbf{6}$ & Wheat & TALEN & MLO & Wang et al., 2016 \\
\hline $\mathbf{7}$ & Potato & TALEN & ALS & Nicolia et al., 2015 \\
\hline
\end{tabular}

Table.4 Successful examples of genome editing in plants using Cas9/sg RNA

\begin{tabular}{|c|c|c|c|c|}
\hline S. No & Plant Name & Nuclease Type & Targeted Gene & References \\
\hline 1 & Soya bean & Cas9/sgRNA & $\begin{array}{l}\text { GFP (transgene), } \\
\text { miR1514, miR1509 }\end{array}$ & Jacobs et al., 2015 \\
\hline 2 & Sorghum & Cas9/sgRNA & DsRED2 & Jiang et al., 2013 \\
\hline 3 & Sweet orange & Cas9/sgRNA & PDS & Jia and Wang, 2014 \\
\hline 4 & Cotton & Cas9/sgRNA & CLA1, VP & Chen et al., 2017 \\
\hline 5 & Tomato & Cas9/sgRNA & $\begin{array}{l}\text { SHR, GFP (transgene), } \\
\text { AGO, 08g041770, 07g021170, } \\
\text { 12g044760, RIN, SIIAA9 }\end{array}$ & $\begin{array}{l}\text { Brooks } \text { et al., } 2014 \\
\text { Ito } \text { et al., } 2015 \\
\text { Ron } \text { et al., } 2014 \\
\text { Ueta } \text { et al., } 2017\end{array}$ \\
\hline 6 & Wheat (Durum) & Cas9/sgRNA & GASR7 & Zhang et al., 2016 \\
\hline 7 & Populus & Cas9/sgRNA & 4CL1, 4CL2, 4CL5 & Zhou et al., 2015 \\
\hline 8 & Arabidopsis & Cas9/sgRNA & FT, SPL4, ABP1 & $\begin{array}{l}\text { Hyun } \text { et al., } 2015 \\
\text { Gao } \text { et al., } 2015\end{array}$ \\
\hline 9 & N. tabacum & Cas9/sgRNA & PDS, PDR6 & Gao et al., 2015 \\
\hline 10 & Rice & Cas9/sgRNA & $\begin{array}{l}\text { MPK1, MPK2, MPK5, MPK6, PDS, } \\
\text { SWEET11, BEL }\end{array}$ & $\begin{array}{l}\text { Ma et al., } 2017 \\
\text { Xu } \text { et al., } 2014 \\
\text { Xie } \text { et al., } 2015\end{array}$ \\
\hline 11 & Wheat (common) & Cas9/sgRNA & GASR7, GW2, DEP1, NAC2, PIN1, LOX2, & Zhang et al., 2016 \\
\hline 12 & Grape & Cas9/sgRNA & $\mathrm{IdnDH}$ & Ren et al., 2016 \\
\hline 13 & Lotus japonicus & Cas9/sgRNA & SYMRK, LjLb1, LjLb2, LjLb3 & Wang et al., 2016 \\
\hline 14 & Petunia & Cas9/sgRNA & NR & Subburaj et al., 2016 \\
\hline 15 & Maize & Cas9/sgRNA & ARGOS8 & $\begin{array}{l}\text { Shi } \text { et al., } 2017 \\
\text { Char } \text { et al., } 2017\end{array}$ \\
\hline
\end{tabular}


Fig.1 Genome editing with designer nucleases. Specific site can be repaired either by nonhomologous end joining (NHEJ) or homologous recombination (Amardeep et al., 2017)

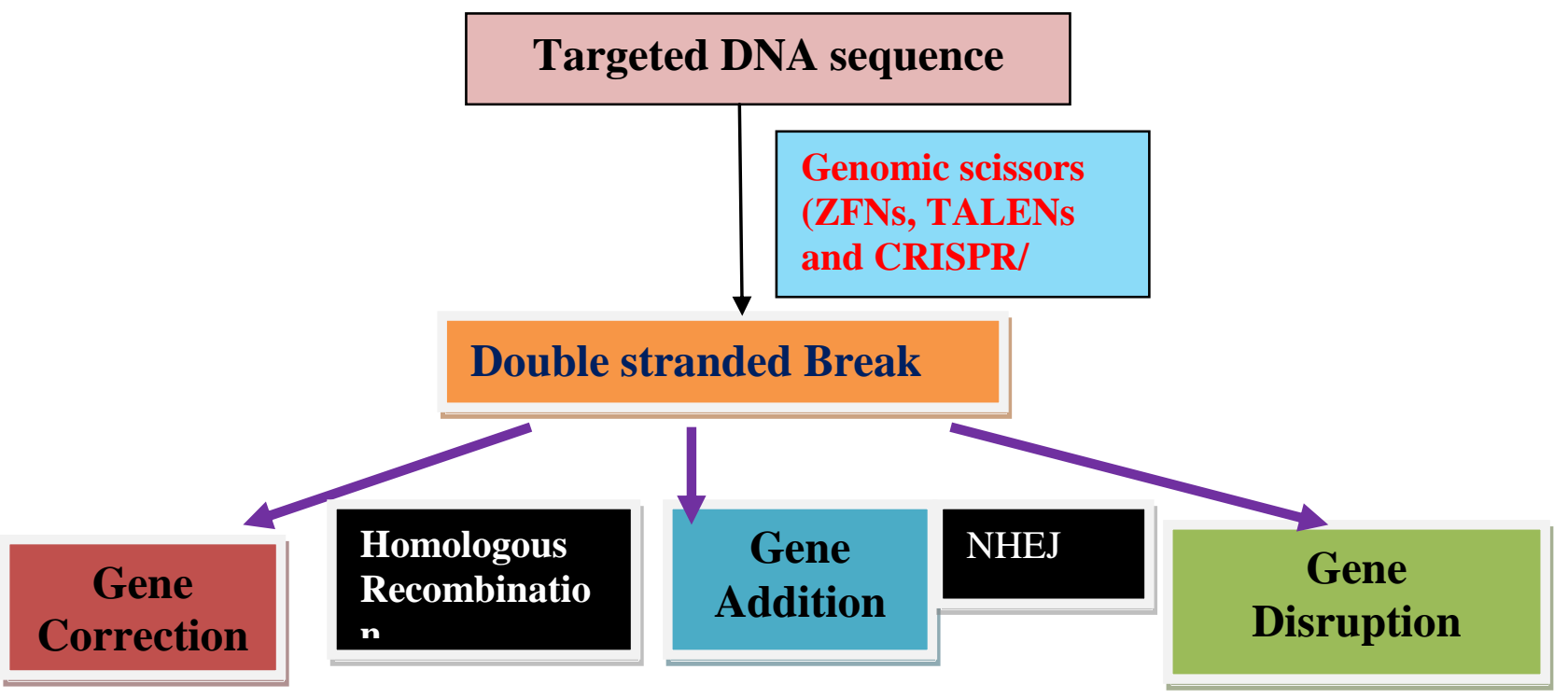

Fig.2 Structure of zinc finger nuclease and mechanism of gene editing (Amardeep et al., 2017)

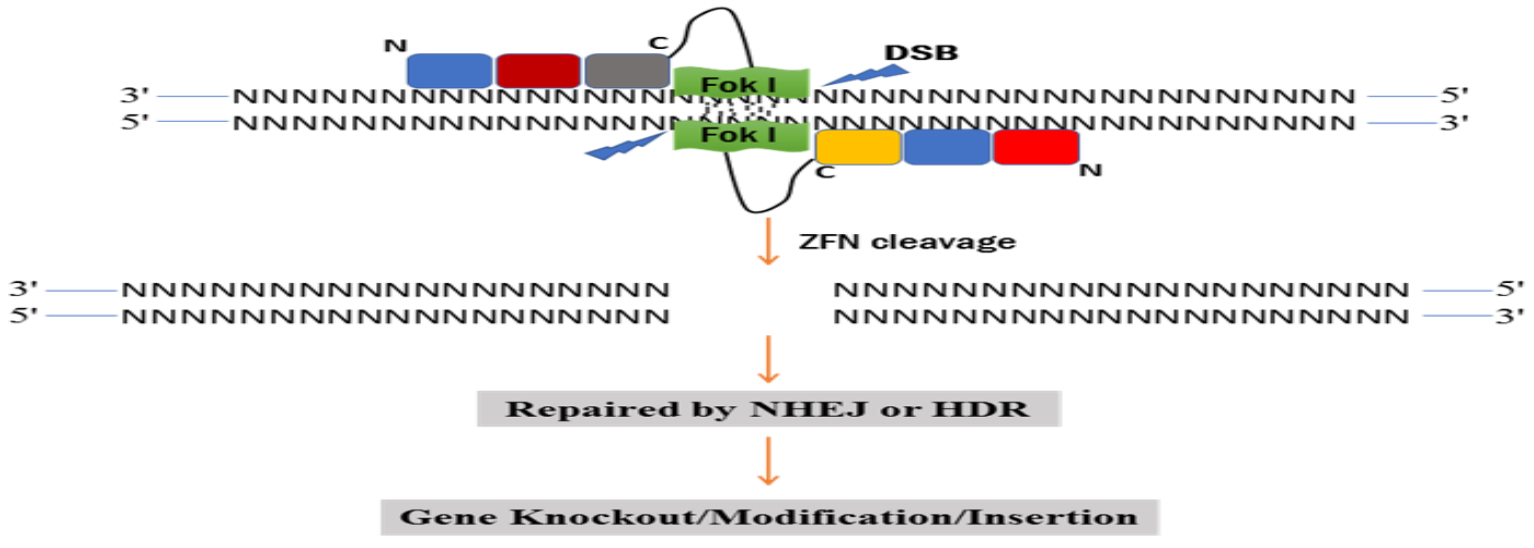

Fig.3 TALENs bind and cleave as dimers on a target DNA site (Amardeep et al., 2017)

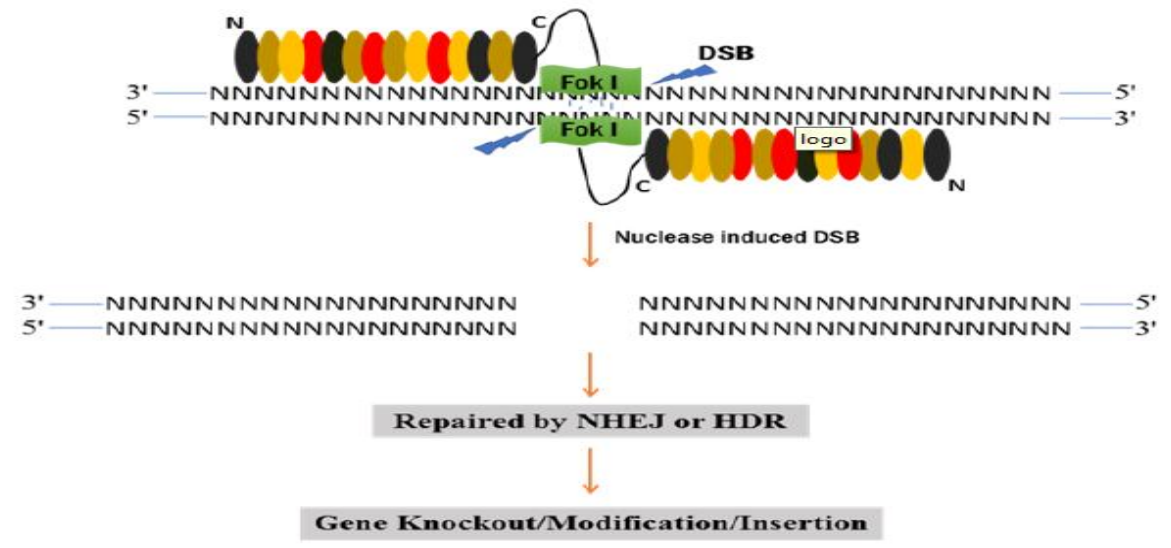


Fig.4 RNA-guided DNA cleavage by Cas9 (Amardeep et al., 2017)

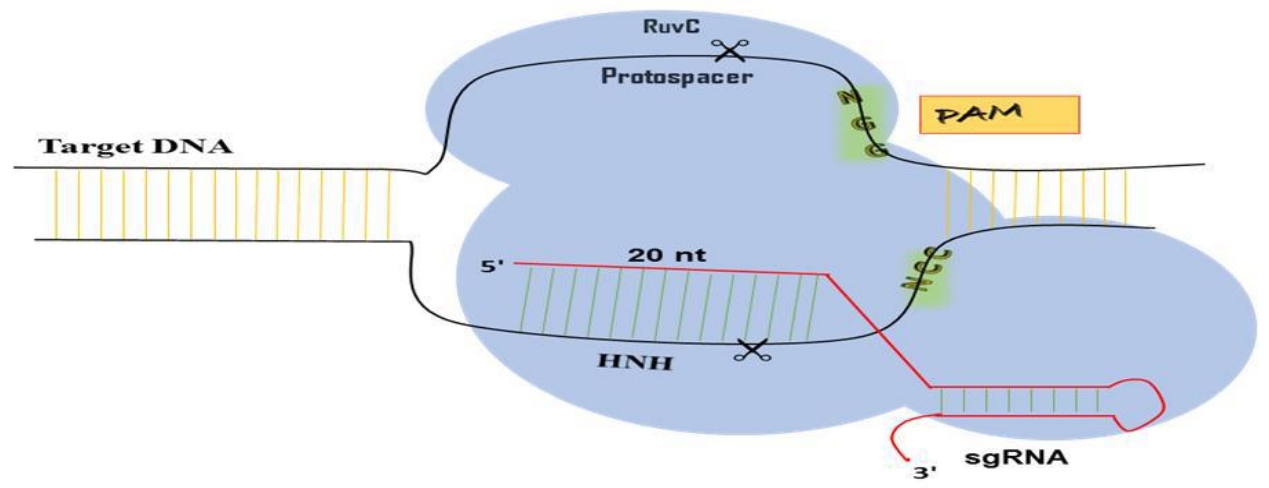

Conclusion and future thrust are as follows:

Genome editing tools have proved to be beneficial for functional genomics as well as crop improvement. Although, there are several limitation and considerations for genome editing technologies. High efficiency in genome editing has been translated into the quantity or screened plants in order to get the desired modification. Among various Genome Editing Systems including TALEN's, ZFN's and CRISPR-cas9, CRISPR-cas9 based platforms have proved to be more competent and less expensive and the studies about plants are made in more significant way with the development of new and improved techniques. These technologies assure to amplify and change any genome. From more fruitful research in future the understanding of multiple CRISPR cas9 system should be explored. The simplicity, flexibility, versatility, and efficiency, of CRISPR/Cas9 genome editing system will help to overstep the potential of previous genome editing systems. For crop improvement these tools are becoming more popular molecular tools of choice. These editing systems are being harnessed for unprecedented understanding of plant biology and crop yield improvement through rapid and targeted mutagenesis and associated breeding (Belhaj et al., 2015; Huang et al., 2016).
No ethical issue is involved with genome editing in plants compared with clinical and medical research, and thus it is more suitable for applied research. To minimize the offtarget effects and to make delivery methods more efficient efforts can be made further. A key question is there that the products of genome modifications made by editing will get greater public acceptance as compared to earlier GMOs.

\section{References}

Allen, B.G. and Weeks, D L. 2009. Bacteriophage phiC31 integrase mediated transgenesis in Xenopus laevis for protein expression at endogenous levels. Methods in Molecular Biology, 518: 113-122.

Allen, B.G. and Weeks, D.L. 2005. Transgenic Xenopus laevis embryos can be generated using phiC31 integrase. Nature Methods, 2: 975-979.

Amardeep, Zaidi, K., Sharma, S. and Sharma, V. 2017. Designer Nucleases for Genome Editing in Plants: Different Approaches and Applications. International Journal of Pure \& Applied Bioscience, 5(6): 1389-1402.

Araki, K., Araki, M., Miyazaki, J. and Vassalli, P. 1995. Site specific recombination of a transgene in fertilized eggs by transient expression 
of Cre recombinase. Proceedings of National Academy of Sciences, 92: 160164.

Ashworth, J., Taylor, G.K., Havranek, J.J., Quadri, S.A., Stoddard, B.L. and Baker, D. 2010. Computational reprogramming of homing endonuclease specificity at multiple adjacent base pairs. Nucleic Acids Research, 38(16): 5601- 5608.

Belhaj, K., Chaparro-Garcia, A., Kamoun, S., Patron, N.J. and Nekrasov, V. 2015. "Editing plant genomes with CRISPR/Cas9." Current Opinion in Biotechnology, 32: 76-84.

Bhaya, D., Davison, M. and Rodolphe, B. 2011. CRISPR-Cas systems in bacteria and archaea: versatile small RNAs for adaptive defense and regulation. Annual Review of Genetics, 45: 273-297.

Bibikova, M., Beumer, K., Trautman, J.K. and Carroll, D. 2003. Enhancing gene targeting with designed zinc finger nucleases. Science, 300(5620): 764.

Boch, J. and Bonas, U. 2010. Xanthomonas AvrBs3 family-type III effectors: discovery and function. Annual Review of Phytopathology, 48: 419-436.

Bolotin, A., Quinquis, B., Sorokin, A. and Ehrlich, S.D. 2005. Clustered regularly interspaced short palindrome repeats (CRISPRs) have spacers of extra chromosomal origin. Microbiology, 151: 2551-2561.

Borrelli, V.M.G., Brambilla, V., Rogowsky P., Marocco, A. and Lanubile, A. 2018. The Enhancement of Plant Disease Resistance Using CRISPR/Cas9 Technology. Frontiers in Plant Science, 9(1245): 1-15.

Brooks, C., Nekrasov, V., Lippman, Z.B. and VanEck, J. 2014. Efficient gene editing in tomato in the first generation using the clustered regularly interspaced short palindromic repeats/CRISPRassociated 9 system. Plant Physiology, 166(3): 1292-1297.
Capecchi, M.R. 2005. Gene targeting in mice: functional analysis of the mammalian genome for the twenty-first century. Nature Reviews Genetics, 6: 507-512.

Carroll, D. 2011. Genome engineering with zinc-finger nucleases. Genetics, 188: 773-782.

Cermak, T., Doyle, E.L., Christian, M., Wang, L., Zhang, Y., Schmidt, C., Baller, J.A., Somia, N.V., Bogdanove, A.J. and Voytas, D.F. 2011. Efficient design and assembly of custom TALEN and other TAL effector-based constructs for DNA targeting. Nucleic Acids Research, 39(12): e82.

Char, S.N., Neelakandan, A.K., Nahampun, H., Frame, B., Main, M., Spalding, M.H., Becraft, P.W., Meyers, B.C., Walbot, V. and Wang, K. 2017. An Agrobacterium delivered CRISPR/Cas9 system for high-frequency targeted mutagenesis in maize. Plant Biotechnology Journal, 15(2): 257-268.

Char, S.N., Unger-Wallace, E., Frame, B., Briggs, S.A., Main, M., Spalding, M.H., Vollbrecht, E., Wang, K. and Yang, B. 2015. Heritable site-specific mutagenesis using TALENs in maize. Plant Biotechnology Journal, 13(7): 1002-1010.

Chen, B., Hu, J., Almeida, R., et al., 2016. Expanding the CRISPR imaging toolset with Staphylococcus aureus Cas9 for simultaneous imaging of multiple genomic loci. Nucleic Acids Research, 44(8): e75.

Chen, L., Tang, L., Xiang, H., Jin, L., Li, Q., Dong, Y., Wang, W. and Zhang, G. 2014. Advances in genome editing technology and its promising application in evolutionary and ecological studies. GigaScience, 3: 2434.

Chen, X., Lu, X., Shu, N., Wang, S., Wang, J., Wang, D., Guo, L. and Ye, W. 2017. Targeted mutagenesis in cotton 
(Gossypium hirsutum L.) using the CRISPR/Cas9 system. Scientific Reports, 7: 44304.

Chevalier, B.S., Kortemme, T., Chadsey, M.S. et al., 2002. Design, activity, and structure of a highly specific artificial endonuclease. Molecular Cell, 10: 895905.

Cho, S.W., Kim, S., Kim, J.M. and Kim, J.S. 2013. Targeted genome engineering in human cells with the Cas9 RNA-guided endonuclease. Nature Biotechnology, 31: 230-232.

Christian, M., Cermak, T., Doyle, E.L., Schmidt, C., Zhang, F. and Hummel, A. 2010. Targeting DNA double-strand breaks with TAL effector nucleases. Genetics, 186: 757-761.

Cong, L., Ran, F.A., Cox, D., et al., 2013. Multiplex genome engineering using CRISPR/Cas systems. Science, 339: 819-823.

Curtin, S.J., Anderson, J.E., Starker, C.G., Baltes, N.J., Mani, D., Voytas, D.F. and Stupar, R.M. 2013. Targeted mutagenesis for functional analysis of gene duplication in legumes. Methods in Molecular Biology, 1069: 25-42.

Curtin, S.J., Zhang, F., Sander, J.D., Haun, W.J., Starker, C., Baltes, N.J., Reyon, D., Dahlborg, E.J., Goodwin, M.J., Coffman, A.P., Dobbs, D., Joung, J.K., Voytas, D.F. and Stupar, R.M. 2011. Targeted mutagenesis of duplicated genes in soybean with zinc-finger nucleases, Plant Physiology, 156: 466-473.

D'Halluin, K., Vanderstraeten, C., Van, Hulle, J., Rosolowska, J., Van Den Brande, I., Pennewaert, A., D'Hont, K., Bossut, M., Jantz, D., Ruiter, R. and Broadhvest, J. 2013. Targeted molecular trait stacking in cotton through targeted double-strand break induction. Plant Biotechnology Journal,
11: 933-941.

Dietzl, G., Chen, D., Schnorrer, F., Su, K.C., Barinova, Y., Fellner, M., Gasser, B., Kinsey, K., Oppel, S., Scheiblauer, S., Couto, A., Marra, V., Keleman, K. and Dickson, B.J. 2007. A genome-wide transgenic RNAi library for conditional gene inactivation in Drosophila. Nature, 448 (7150): 151-156.

Dunwell, J.M. 2014. Genetically modified (GM) crops: European and transatlantic divisions. Molecular Plant Pathology, 15: 119-121.

Engler, C., Gruetzner, R., Kandzia, R. and Marillonnet, S. 2009. Golden gate shuffling: a one-pot DNA shuffling method based on type IIs restriction enzymes. PLoS One, 4(5): e5553.

FAO 2017. The Future of Food and Agriculture - Trends and Challenges. Rome: FAO.

Gaj, T., Charles, A.G. and Carlos, F.B. 2013. ZFN, TALEN and CRISPR/Cas based methods for genome engineering. Trends in Biotechnology, 31(7): 397405.

Gallagher, R.R., Li, Z., Lewis, A.O. and Isaacs, F.J. 2014. Rapid editing and evolution of bacterial genomes using libraries of synthetic DNA. Nature Protocols, 9(10): 2301-2316.

Gao, J., Wang, G., Ma, S., Xie, X., Wu, X., Zhang, X., Wu, Y., Zhao, P. and Xia, Q. 2015. CRISPR/Cas9-mediated targeted mutagenesis in Nicotiana tabacum. Plant Molecular Biology, 87(1-2): 99-110.

Gao, Y., Zhang, Y., Zhang, D., Dai, X., Estelle, M. and Zhao, Y. 2015. Auxin binding protein 1 (ABP1) is not required for either auxin signaling or Arabidopsis development. Proceedings of the National Academy of Sciences, USA. 112(7): 2275-2280.

Gelvin, S.B. 2003. Agrobacterium-mediated plant transformation: the biology behind 
the 'gene-jockeying' tool. Microbiology and Molecular Biology Reviews, 67: 16-37.

Gonczy, P., Echeverri, C., Oegema, K., Coulson, A., Jones, S.J.M., Copley, R.R., Duperon, J., Oegema, J., Brehm, M., Cassin, E., et al., 2000. Functional genomic analysis of cell division in $\mathrm{C}$. elegans using RNAi of genes on chromosome III. Nature, 408(6810): 331-336.

Gurushidze, M., Hensel, G., Hiekel, S., Schedel, S., Valkov, V. and Kumlehn, J. 2014. True-breeding targeted gene knock-out in barley using designer TALE nuclease in haploid cells. PLoS ONE. 9(3): e92046.

Haun, W., Coffman, A., Clasen, B.M., Demorest, Z.L., Lowy, A., Ray, E.,et $a l ., 2014$. Improved soyabean oil quality by targeted mutagenesis of the fatty acid desaturase 2 gene family. Plant Biotechnology journal, 12(7): 934-940.

Hsu, P.D., Scott, D.A., Weinstein, J. A., Ran, F.A., Konermann, S., Agarwala, V., Li, Y., Eli, J., Fine, E. J., Wu, X., Shalem, O., Cradick, T.J., Marraffini, L.A., Bao, G. and Zhang, F. 2013. DNA targeting specificity of RNA-guided Cas9 nucleases. Nature Biotechnology, 31: 827-832.

Huang, S., Weigel, D., Beachy, R.N. and Li, J. 2016. "A proposed regulatory framework for genome-edited crops." Nature Genetics, 48(2): 109-111.

Hyun, Y., Kim, J., Cho, S.W., Choi, Y., Kim, J.S. and Coupland, G. 2015. Site-directed mutagenesis in Arabidopsis thaliana using dividing tissue-targeted RGEN of the CRISPR/Cas system to generate heritable null alleles. Planta, 241(1): 271-284.

Ito, Y., Nishizawa-Yokoi, A., Endo, M., Mikami, M. and Toki, S. 2015. CRISPR/Cas9-mediated mutagenesis of the RIN locus that regulates tomato fruit ripening. Biochemical and Biophysical Research Communications, 467(1): 7682.

Jacobs, T.B., LaFayette, P.R., Schmitz, R.J. and Parrott, W.A. 2015. Targeted genome modifications in soybean with CRISPR/Cas9. BMC Biotechnology, 15: 16.

Jaganathan, D., Ramasamy, K., Sellamuthu, G., Jayabalan, S. and Venkataraman, G. 2018. CRISPR for Crop Improvement: An Update Review. Frontiers in Plant Science, 9(985): 1-15.

James, C. 2014. ISAAA Report on Global Status of Biotech/GM Crops, International Service for the Acquisition Of Agri-biotech Applications (ISAAA).

Jia, H. and Wang, N. 2014. Targeted genome editing of sweet orange using Cas9/sgRNA. PLoS ONE, 9(4): e93806.

Jia, H., Pang, Y., Chen, X. and Fang, R. 2006. Removal of the selectable marker gene from transgenic tobacco plants by expression of cre recombinase from a tobacco mosaic virus vector through agroinfection. Transgenic Research, 15: 375-384.

Jiang, W., Zhou, H., Bi, H., Fromm, M., Yang, B. and Weeks, D.P. 2013. Demonstration of CRISPR/Cas9/ sgRNA-mediated targeted gene modification in Arabidopsis, tobacco, sorghum and rice. Nucleic Acids Research, 41(20): e188.

Jinek, M., Chylinski, K., Fonfara, I., Hauer, M., Doudna, J.A. and Charpentier, E. 2012. A programmable dual-RNAguided DNA endonuclease in adaptive bacterial immunity. Science, 337: 816821.

Jurica, M.S., Monnat, R.J., Jr. and Stoddard, B.L. 1998. DNA recognition and cleavage by the LAGLIDADG homing endonuclease I-Cre I. Molecular Cell, 2: 469-476. 
Kay, S., Hahn, S., Marois, E., Hause, G. and Bonas, U. 2007. A bacterial effector acts as a plant transcription factor and induces a cell size regulator. Science, 318: 648-651.

Kim, Y.G., Cha, J. and Chandrasegaran, S. 1996. Hybrid restriction enzymes: zinc finger fusions to Fok I cleavage domain. Proceedings of National Academy of Science of the United States of America USA, 93: 1156-1160.

Knorre, D.G. and Vlasov, V.V. 1985. Reactive derivatives of nucleic acids and their components as affinity reagents. Russian Chemical Reviews, 54(9): 836-851.

Kumar, V. and Jain, M. 2015. The CRISPRCas system for plant genome editing: advances and opportunities. Journal of Experimental Botany, 66(1): 47-57.

Kumar, V. and Jain, M. 2015. The CRISPRCas system for plant genome editing: advances and opportunities. Journal of Experimental Botany, 66: 47-57.

Kuromori, T., Wada, T., Kamiya, A., Yuguchi, M., Yokouchi, T., Imura, Y., Takabe, H., Sakurai, T., Akiyama, K. and Hirayama, T., et al., 2006. A trial of phenome analysis using 4000 Dsinsertional mutants in genecoding regions of Arabidopsis. Plant Journal, 47: 640-651.

Li, T., Liu, B., Spalding, M.H., Weeks, D.P. and Yang, B. 2012. High-efficiency TALEN based gene editing produces disease-resistant rice. Nature Biotechnology, 30(5): 390-392.

Lor, V.S., Starker, C.G., Voytas, D.F., Weiss, D. and Olszewski, N.E. 2014. Targeted mutagenesis of the tomato PROCERA gene using TALENs. Plant Physioogy, 166: 1288-1291.

Lucht, J.M. 2015. Public Acceptance of Plant Biotechnology and GM Crops. Viruses, 7(8): 4254-4281.

Luo, S.S, Li, J., Stoddard, T.J., Baltes, N.J.,
Demorest, Z.L., Clasen, B.M., Coffman, A., Retterath, A., Mathis, L., Voytas, D.F. and Zhang, F. 2015. Nontransgenic Plant Genome Editing Using Purified Sequence-Specific Nucleases. Molecular Plant, 9: 1425-1427.

Ma, L., Zhang, D., Miao, Q., Yang, J., Xuan, Y. and $\mathrm{Hu}, \mathrm{Y}$. 2017. Essential role of sugar transporter OsSWEET11 during the early stage of rice grain filling. Plant and Cell Physiology, doi:10.1093/pcp/pcx040.

Mak, A.N., Bradley, P., Cernadas, R.A., Bogdanove, A.J. and Stoddard, B.L. 2012. The crystal structure of TAL effector PthXo1 bound to its DNA target. Science, 335: 716-719.

Mali, P., Yang, L., Esvelt, K.M., Aach, J., Guell, M., Dicarlo, J.E., Noeville, J.E. and Chuech, G.M. 2013. RNA-guided human genome engineering via Cas9. Science, 339: 823-826.

Martin, S.E. and Caplen, N.J. 2007. Applications of RNA interference in mammalian systems. Annual Review of Genomics and Human Genetics, 8: 81108.

McManus, M.T. and Sharp, P.A. 2002. Gene silencing inmammals by small interfering RNAs. Nature Review Genetics, 3: 737-747.

Mojica, F.J., Diez-Villasensor, C., GarciaMartinez, J. and Soria, E. 2005. Intervening sequences of regularly spaced prokaryotic repeats derive from foreign genetic elements. Journal of Molecular Evolution, 60: 174-182.

Nemudryi, A.A., Valetdinova, K.R., Medvedev, S.P. and Zakian, S.M. 2014. "TALEN and CRISPR/Cas genome editing systems: tools of discovery." Acta Naturae, 6(22): 19-40.

Nicolia, A., Proux-Wera, E., Ahman, I., Onkokesung, N., Andersson, M., Andreasson, E. and Zhu, L.H. 2015. Targeted gene mutation in tetraploid 
potato through transient TALEN expression in protoplasts. Journal of Biotechnology, 204: 17-24.

Noman, A., Aqeel, M., He, S. 2016. CRISPRCas9: tool for qualitative and quantitative plant genome editing. Frontiers in Plant Science, 7: 1740.

Osakabe, K., Osakabe, Y. and Toki, S. 2010. Site-directed mutagenesis in Arabidopsis using custom-designed zinc finger nucleases, Proceedings of the National Academy of Sciences, USA. 107: 12034-12039.

Pathirana, R. 2011. Plant mutation breeding in agriculture, CAB Reviews, 6: 1-20.

Porteus, M.H. 2006. Mammalian gene targeting with designed zinc finger nucleases. Molecular Therapy, 13: 438446.

Pourcel, C., Salvignol, G. and Vergnaud, G. 2005. CRISPR elements in Yersinia pestis acquire new repeats by preferential uptake of bacteriophages DNA, and provide additional tools for evolutionary studies. Microbiology, 151: 653-663.

Puchta, H. and Hohn, B. 2010. Breaking news: Plants mutate right on target. Proceedings of the National Academy of Sciences of the United States of America, 107(26): 11657-11658.

Ray, D.K., Mueller, N.D., West, P.C. and Foley, J.A. 2013. Yield trends are insufficient to double global crop production by 2050. PLoS ONE, 8(6): e66428.

Rebar, E.J., Huang, Y., Hickey, R., Nath, A.K., Meoli, D., Nath, S., Chen, B., Xu, L., Liang, Y. and Jamieson, A.C., et al., 2002. Induction of angiogenesis in a mouse model using engineering transcription factors. Nature Medicine, 8: $1427-1432$.

Ren, C., Liu, X., Zhang, Z., Wang, Y., Duan, W., Li, S. and Liang, Z. 2016. CRISPR/Cas9-mediated efficient targeted mutagenesis in Chardonnay (Vitis vinifera L.). Scientific Reports, 6: 32289.

Reyon, D., Tsai, S.Q., Khayter, C., Foden, J.A., Sander, J.D. and Joung, J.K. 2012. FLASH assembly of TALENs enables high throughput genome editing. Nature Biotechnology, 30(5): 460-465.

Ron, M., Kajala, K., Pauluzzi, G., Wang, D., Reynoso, M.A., Zumstein, K., Garcha, J., Winte, S., Masson, H., Inagaki, S., Federici, F., Sinha, N., Deal, R.B., Bailey-Serres, J. and Brady, S.M. 2014. Hairy root transformation using Agrobacterium rhizogenes as a tool for exploring cell type-specific gene expression and function using tomato as a model. Plant Physiology, 166(2): 455-469.

Rousseau, C., Gonnet, M., Le Romancer, M. and Nicolas, J. 2009. CRISPI: a CRISPR interactive database. Bioinformatics, 25: 3317-3318.

Sander, J.D., Dahlborg, E.J., Goodwin, M.J., Cade, L., Zhang, F., Cifuentes, D., Curtin, S.J., Blackburn, J.S., Thibodeau-Beganny, S., Qi, Y., Pierick, C.J., Hoffman, E., Maeder, M.L., Khayter, C., Reyon, D., Dobbs, D., Langenau, D.M., Stupar, R.M., Giraldez, A.J., Voytas, D.F., Peterson, R.T., Yeh, J.J. and Joung, J.K. 2011. Selection-free zinc-finger-nuclease engineering by context-dependent assembly (CoDA). Nature Methods, 8: 67-69.

Sauer, N.J., Mozoruk, J., Miller, R.B., et al., 2016. Oligonucleotide directed mutagenesis for precision gene editing. Plant Biotechnology Journal, 14(2): 496-502.

Schaeffer, S.M. and Nakata, P.A. 2015. CRISPR-mediated genome editing and gene replacement in plants: transitioning from lab to field. Plant Science, 240: 130-142. 
Seligman, L.M., Chisholm, K.M., Chevalier, B.S. et al., 2002. Mutations altering the cleavage specificity of a homing endonuclease. Nucleic Acids Research, 30: 3870-3879.

Shah, T., Andleeb, T., Lateef, S. and Noor, M.A. 2018. Genome editing in plants: Advancing crop transformation and overview of tools. Plant Physiology and Biochemistry, 131: 12-21.

Shan, Q., Wang, Y., Chen, K., Liang, Z., Li, J., Zhang, Y., Zhang, K., Liu, J., Voytas, D.F. and Zheng, X. 2013. Rapid and efficient gene modification in rice and Brachypodium using TALENs. Molecular Plants, 6(4): 1365-1368.

Shi, J., Gao, H., Wang, H., Lafitte, H.R., Archibald, R.L, Yang, M., Hakimi, S.M., Mo, H. and Habben, J.E. 2017. ARGOS8 variants generated by CRISPR-Cas9 improve maize grain yield under field drought stress conditions. Plant Biotechnology Journal, 15(2): 207-216.

Shukla, V.K., Doyon, Y., Miller, J.C., DeKelver, R.C., Moehle, E.A., Worden, S.E., Mitchell, J.C., Arnold, N.L., Gopalan, S., Meng, X., Choi, V.M., Rock, J.M., Wu, Y.Y., Katibah, G.E., Zhifang, G., McCaskill, D., Simpson, M.A., Blakeslee, B., Greenwalt, S.A., Butler, H.J., Hinkley, S.J., Zhang, L., Rebar, E.J., Gregory, P.D. and Urnov, F.D. 2009. Precise genome modification in the crop species Zea mays using zinc-finger nucleases. Nature, 459: 437-441.

Smith, J., Grizot, S., Arnould, S. et al., 2006. A combinatorial approach to create artificial homing endonucleases cleaving chosen sequences. Nucleic Acids Research, 34: 1-12.

Smith, J.J., Jantz, D. and Hellinga, W.H. 2011. Methods of cleaving DNA with rationally-designed meganucleases. United States Patent.
http://www.google.com/patents/US8143 015.

Subburaj, S., Chung, S.J., Lee, C., Ryu, S.M., Kim, D.H., Kim, J.S., Bae, S. and Lee, G.J. 2016. Site-directed mutagenesis in Petunia $\mathrm{x}$ hybrida protoplast system using direct delivery of purified recombinant Cas9 ribonucleoproteins. Plant Cell Reports, 35(7): 1535-1344.

Symington, L.S. and Gautier, J. 2011. Double-strand break end resection and repair pathway choice. Annual Review Genetics, 45: 247-271.

Townsend, J.A., Wright, D.A., Winfrey, R.J., Fu, F., Maeder, M.L., Joung, J.K. and Voytas, D.F. 2009. High-frequency modification of plant genes using engineered zinc-finger nucleases. Nature, 459: 442-445.

Ueta, R., Abe, C., Watanabe, T., Sugano, S.S., Ishihara, R., Ezura, H., Osakabe, Y. and Osakabe, K. 2017. Rapid breeding of parthenocarpic tomato plants using CRISPR/Cas9. Scientific Reports, 7(1): 507.

Urnov, F.D. et al., 2010. Genome editing with engineered zinc finger nucleases. Nature Review Genetics, 11: 636-646.

Verma, S.R. 2013. Genetically Modified Plants: Public and Scientific Perceptions, 2013. International Society Research Notices Biotechnology. Article ID 820671, 11 pages

Voytas, D.F. 2013. Plant genome engineering with sequence-specific nucleases. Annual Review of Plant Biology, 64: 327-350.

Voytas, D.F. and Gao, C. 2014. Precision genome engineering and agriculture: opportunities and regulatory challenges. PLOS Biology, 12(6): 1-6.

Wang, L., Wang, L., Tan, Q., Fan, Q., Zhu, H., Hong, Z., Zhang, Z. and Duanmu, D. 2016. Efficient inactivation of symbiotic nitrogen fixation related genes in Lotus japonicus using 
CRISPR-Cas9. Frontiers in Plant Science, 7: 1333.

Wang, Y., Yau, Y., Perkins-Balding, D. and Thomson, J.G. 2011. Recombinase technology: applications and possibilities. Plant Cell Reports, 30(3): 267-285.

Weber, E., Engler, C., Gruetzner, R., Werner, S. and Marillonnet, S. 2011. A modular cloning system for standardized assembly of multigene constructs. PLoS One, 6(2): e16765.

Weeks, D.P., Spalding, M.H. and Yang, B. 2016. Use of designer nucleases for targeted gene and genome editing in plants. Plant Biotechnology journal, 14 (2): 483-495.

Wiedenheft, B., Sternberg, S.H. and Doudna, J.A. 2012. RNA guided genetic silencing systems in bacteria and archaea. Nature, 482: 331-338.

Witzany, G. 2011. The agents of natural genome editing. Journal of Molecular Cell Biology, 3(3): 181-189.

Wu, C., Li, X., Yuan, W., Chen, G., Kilian, A., Li, J., Xu, C., Li, X., Zhou, D.X., Wang, S. and et al., 2003. Development of enhancer trap lines for functional analysis of the rice genome. Plant Journal, 35: 418-427.

Xie, K., Minkenberg, B. and Yang, Y. 2015. Boosting CRISPR/Cas9 multiplex editing capability with the endogenous tRNA-processing system. Proceedings of the National Academy of Sciences, USA. 112(11): 3570-3575.
Xu, R., Li, H., Qin, R., Wang, L., Li, L., Wei, P. and Yang, J. 2014. Gene targeting using the Agrobacterium tumefaciens-mediated CRISPR-Cas system in rice. Rice (NY), 7(1): 5.

Yang, Y., Li, Y., and Wu, C. 2013. Genomic resources for functional analyses of the rice genome. Current Opinion in Plant Biology, 16: 157-163.

Zhang, F., Maeder, M.L., Unger-Wallace, E., Hoshaw, J.P., Reyon, D., Christian, M., Li, X., Pierick, C. J., Dobbs, D., Peterson, T., Joung, J.K. and Voytas, D.F. 2010. High frequency targeted mutagenesis in Arabidopsis thaliana using zinc finger nucleases. Proceedings of the National Academy of Sciences, USA. 107: 12028-12033.

Zhang, Y., Liang, Z., Zong, Y., Wang, Y., Liu, J., Chen, K., Qiu, J. L. and Gao, C. 2016. Efficient and transgene-free genome editing in wheat through transient expression of CRISPR/Cas9 DNA or RNA. Nature Communication, 7: 12617.

Zhao, H. and Wolt, J.D. 2017. Risk associated with off-target plant genome editing and methods for its limitation. Emerging Topics in Life Sciences, 1: 231-240.

Zhou, X., Jacobs, T.B., Xue, L.J., Harding, S.A. and Tsai, C.J. 2015. Exploiting SNPs for biallelic CRISPR mutations in the outcrossing woody perennial Populus reveals 4-coumarate:CoA ligase specificity and redundancy. New Phytologist, 208(2): 298-301.

\section{How to cite this article:}

Lokesh Yadav, Promil Kapoor and Ashwani Kumar. 2019. Genome Editing: Methods and Application in Plant Pathology. Int.J.Curr.Microbiol.App.Sci. 8(05): 1301-1319. doi: https://doi.org/10.20546/ijcmas.2019.805.149 